\title{
THE DETERMINATION OF PHENOLIC COMPOUNDS IN ARTICHOKE FLOWER HEAD EXTRACTS BY HPLC GC/MS TECHNIQUE
}

\author{
Andrei Fedosov ${ }^{1}$, Oleksandra Kyslychenko ${ }^{1}$, Andrei Gudzenko ${ }^{2}$, Olga Semenchenko ${ }^{2}$, \\ Victoriia Kyslychenko
}

\author{
${ }^{1}$ National University of Pharmacy, Kharkiv, Ukraine \\ ${ }^{2}$ Government Agency "Institute of Pharmacology and Toxicology, National Academy of \\ Medical Science of Ukraine", Kyiv, Ukraine
}

\begin{abstract}
AIM: The aim of the research was the study of component composition of artichoke extract and its standardization.

MATERIALS AND METHODS: Dry artichoke flower heads (inflorescences) was the plant raw material which was selected as the object of research. Methanol extracts and methanol extracts after hydrolysis were analyzed by HPLC GC/MS technique.

RESULTS AND CONCLUSIONS: As a result of the research, eight compounds such as luteolin-7-glucoside, luteolin, apifenin-7-glucoside, hy peroside, rutin, caffeic acid, chlorogenic acid and rosmarinic acid were detected in the tested solutions. Four phenolic compounds such as apigenin-7-glucoside, luteolin, chlorogenic acid and luteolin-7-glucoside were identified in the studied methanol extract after hydrolysis. HPLC technique is the validated quality control technique of the obtained extract.
\end{abstract}

Keywords: artichoke, flower heads, luteolin-7-glucoside, apigenin-7-glucoside, caffeic acid, chlorogenic acid, HPLC GC/MS

\section{INTRODUCTION}

Being a popular ingredient in Mediterranean cuisine, artichoke was used as a treatment agent since ancient times $(1,10)$. Artichoke had an effect on gastro-intestinal tract dysfunction and disorders $(2,5,10,14,15)$. This delicious plant showed choleretic, diuretic, and antirheumatic activities as well as a coagulant effect in liver and kidneys (10-12,15). Despite wide application in official and folk medicine

Address for correspondence:

Victoriia Kyslychenko

National University of Pharmacy

53 Pushkinska str.

61002 Kharkiv, Ukraine

e-mail:cncvc@mail.ru

Received: June 7, 2016

Accepted: November 4, 2016
(15), artichoke flower heads are still of great interest among the scientists. During the first part of twentieth century some new effects of artichoke were discovered. This plant turned out to improve liver functioning, protect from liver fat degeneration caused by arsenic compounds as well as decrease cholesterol level $(3,4,6,13,15)$. 1990s was an important period in artichoke studies. This decade went into history as the time of cynarin structure discovery and exploration of cell-protection action on isolated secondary hepatocytes and cholesterol biosynthesis decrease $(9,10)$.

The lack of side-effects in combination with fetus protection activity makes artichoke remedies and dietary products an important part of a therapy during pregnancy $(10,15)$. However, an ongoing interest in artichoke demands precise sample preparation procedures for extracts obtaining further standard- 
ization of the extracts for future use in a prospective artichoke drug design.

\section{MATERIALS AND METHODS}

Dry artichoke flower heads (inflorescences) was the plant raw material which was selected as the object of research.

The studied solutions were prepared in the following way (7).

\section{Methanol Solution Preparation}

$5 \mathrm{~g}$ of plant raw material - dry artichoke flower heads (inflorescences) was put into a round-bottom flask with further addition of $125.0 \mathrm{ml}$ of methanol and boiling it in a water bath with a reflux condenser for 1 hour. Later on it was cooled, filtered through matograph which consisted of a pump unit G1312A, degasser G1322A, column thermostat G1316A, autosampler G1367B, diode-matrix detector G1315D and quadrupole mass spectrometer Agilent 6130. Chromatography was carried out under such conditions: a column made of a stainless steel C18 SunFire (150 $\mathrm{x} 4.6 \mathrm{~mm}, 3.5 \mu \mathrm{m}$ ); the column temperature $-38^{\circ} \mathrm{C}$; diode-matrix detector detection wavelength was 254 $\mathrm{nm}, 330 \mathrm{~nm}, 350 \mathrm{~nm}, 360 \mathrm{~nm}, 370 \mathrm{~nm}$. Mass detector detection conditions were the following: ionization - electric spray, scanning in the range of 150$800 \mathrm{~m} / \mathrm{z}$ (positive and negative ionization); fragmentation - 70; gain -1.0; the flow rate of a mobile phase was $1 \mathrm{ml} / \mathrm{min}$; the injected sample volume was $50 \mu \mathrm{l}$.

The mobile phase was the following:

\begin{tabular}{l|c|c|c|}
\hline Time, minutes & $\begin{array}{c}\text { Mobile phase A, \% } \\
\text { (turnover/turnover) }\end{array}$ & $\begin{array}{c}\text { Mobile phase B, \% } \\
\text { (turnover/turnover) }\end{array}$ & Mode \\
$0 \rightarrow 1$ & 92 & 8 & isocratic \\
$1 \rightarrow 15$ & $92 \rightarrow 70$ & $8 \rightarrow 30$ & gradient \\
$15 \rightarrow 25$ & $70 \rightarrow 0$ & $30 \rightarrow 100$ & gradient \\
$25 \rightarrow 33$ & 0 & 100 & isocratic \\
$33 \rightarrow 33.5$ & $0 \rightarrow 92$ & $100 \rightarrow 8$ & gradient \\
\hline
\end{tabular}

Mobile phase A - 0.1\% formic acid solution;

Mobile phase B-0.1\% formic acid solution in the mixture (acetonitrile:methanol 1:1).

"blue stripe" paper filter (solution 1). The solvent was added to $5.0 \mathrm{ml}$ of the obtained solution in amount enough to get $10.0 \mathrm{ml}$ in total volume.

\section{Extract Preparation after Hydrolysis}

$5.0 \mathrm{ml}$ of solution 1 was put into a round-bottom flask with the further addition of $5.0 \mathrm{ml}$ of hydrochloric acid. The obtained solution was boiled in a water bath with a reflux condenser for $30 \mathrm{~min}$. Afterwards it was cooled and put into a $25 \mathrm{ml}$ volumetric flask. The volume was increased with methanol up to the flask mark, then mixed and filtered through "blue stripe" paper filter. The solvent was added to $5.0 \mathrm{ml}$ of the obtained solution in amount enough to get $10.0 \mathrm{ml}$ in total volume. The next step was conduction of a chromatographic analysis.

The chromatographic study of the tested extracts and standard samples solutions was carried out with the help of Agilent 1200 LC/MSD chro-
Hyperoside, rutin, apigenin-7-glucoside, luteolin-7-glucoside and luteolin solutions as well as caffeic acid, rosmarinic acid and chlorogenic acid solutions in methanol were used as standard solutions.

While working, the following reagents were used: acetonitrile and methanol for gradient chromatography ("FLUKA" (Germany)); formic acid ("FLUKA" (Germany)); rectified ethanol (according to the Pharmacopoeia requirements), and water.

The obtained data were analyzed using Student's t-test.

\section{RESULTS AND DISCUSSION}

Table 1 shows the data regarding the retention time of standard substances under the conditions of the studied chromatography technique.

The chromatograms of the standard compounds are shown in Fig. 1-8. 
Andrei Fedosov, Oleksandra Kyslychenko, Andrei Gudzenko et all.

Table 1. Physicochemical characteristics of phenolic compounds

\begin{tabular}{llcc} 
Compound Name & Formula & Molecular mass & {$[\mathrm{M}-\mathrm{H}]^{-}(\mathrm{m} / z)$} \\
Hyperoside & $\mathrm{C}_{27} \mathrm{H}_{30} \mathrm{O}_{16}$ & 610.15 & 465 \\
Rutin & $\mathrm{C}_{15} \mathrm{H}_{10} \mathrm{O}_{6}$ & 286.05 & 611 \\
Luteolin & $\mathrm{C}_{21} \mathrm{H}_{20} \mathrm{O}_{11}$ & 448.10 & 287 \\
Luteolin-7-glucoside & $\mathrm{C}_{21} \mathrm{H}_{20} \mathrm{O}_{10}$ & 432.11 & 449 \\
Apigenin-7-glucoside & $\mathrm{C}_{9} \mathrm{H}_{8} \mathrm{O}_{4}$ & 180.04 & 333 \\
Chlorogenic acid & $\mathrm{C}_{16} \mathrm{H}_{18} \mathrm{O}_{9}$ & 354.10 & 355 \\
Caffeic acid & $\mathrm{C}_{18} \mathrm{H}_{16} \mathrm{O}_{8}$ & 360.08 & 179 \\
Rosmarinic acid & $\mathrm{C}_{16} \mathrm{H}_{18} \mathrm{O}_{9}$ & 354.10 & 359 \\
\hline
\end{tabular}

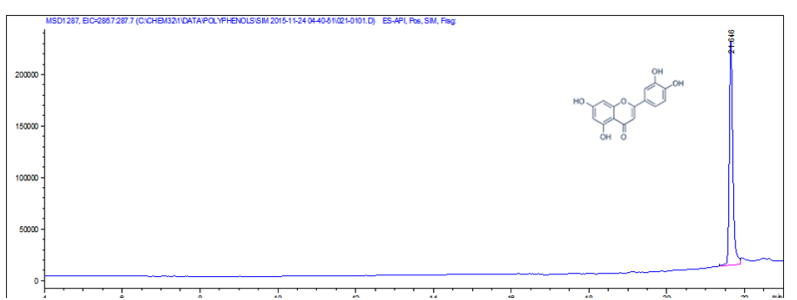

Fig. 1. The chromatogram of luteolin standard solution [+287u]

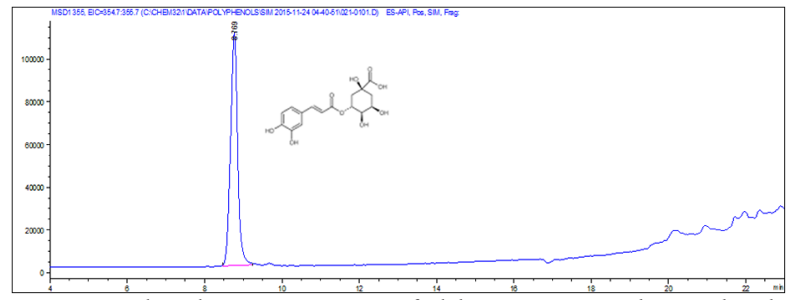

Fig. 2. The chromatogram of chlorogenic acid standard solution [+355u]

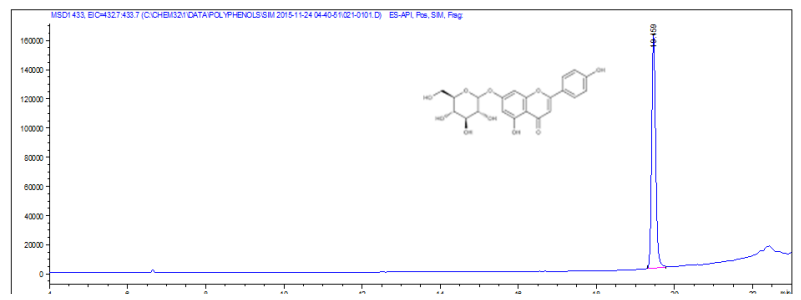

Fig. 3. The chromatogram of apigenin-7-glucoside standard solution [+433u]

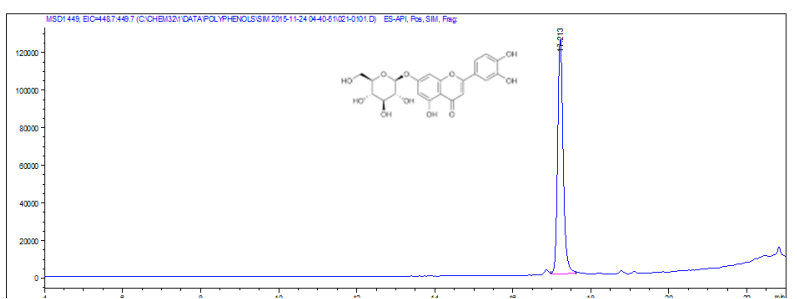

Fig. 4. The chromatogram of luteolin-7-glucoside standard solution [+449u]

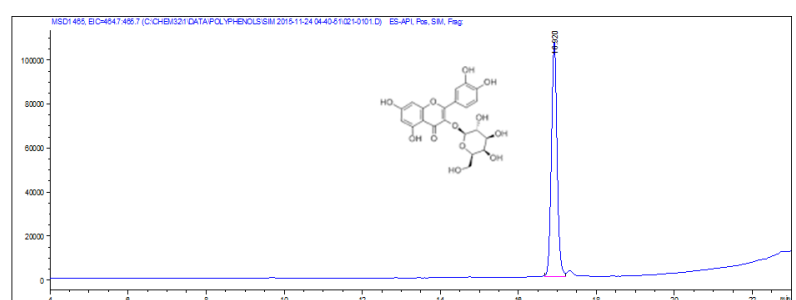

Fig. 5. The chromatogram of hyperoside standard solution [+465u]

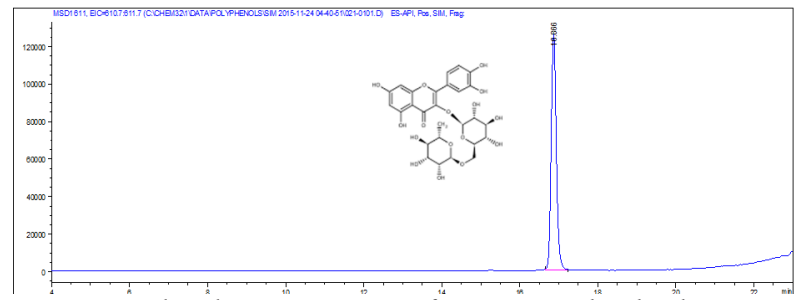

Fig. 6. The chromatogram of rutin standard solution

[+611u]

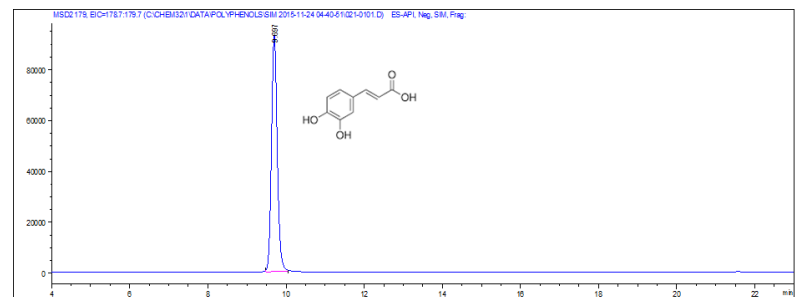

Fig. 7. The chromatogram of the caffeic acid standard solution [-179u]

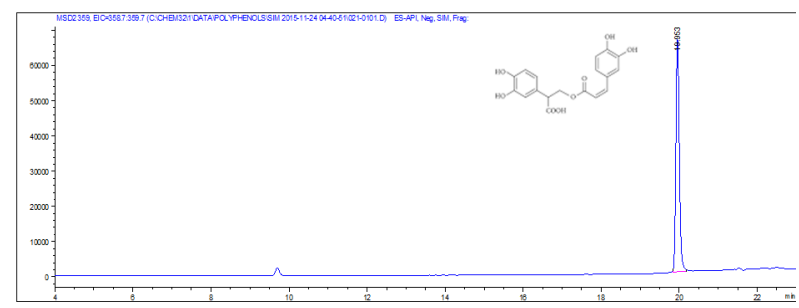

Fig. 8. The chromatogram of the rosmarinic acid standard solution [-359 u] 
Figures 9-10 show chromatograms of the studied solutions. The studied compounds in the solutions tested were identified by retention time as well as by $\mathrm{m} / \mathrm{z}$ index.

Fig. 9 represents the chromatograms of the tested solutions obtained under conditions of positive ionization. Fig. 10 represents the chromatograms of the tested solutions obtained under conditions of negative ionization.

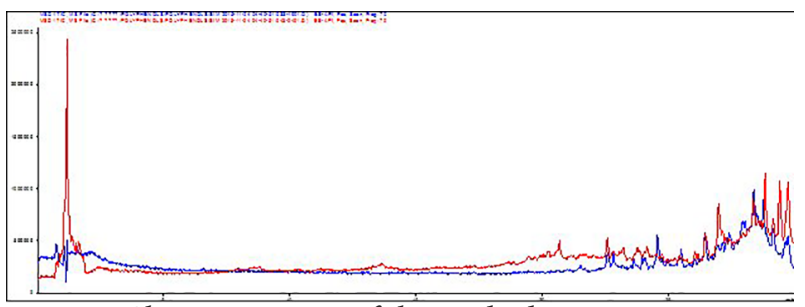

Fig. 9. Chromatograms of the studied extracts, positive ionization. The red line represents the methanol extract; the blue line represents the studied extract after hydrolysis

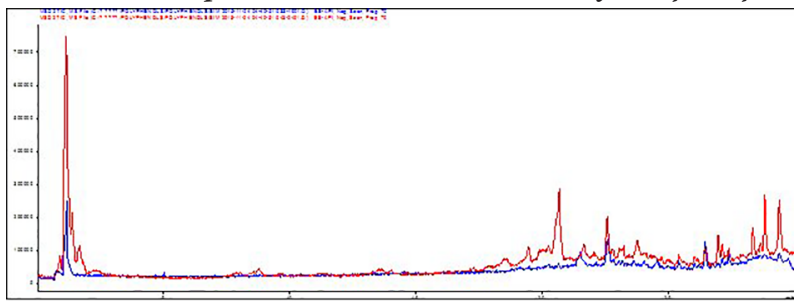

Fig. 10. Chromatograms of the studied extracts, negative ionization. The red line represents the methanol extract; the blue line represents the studied extract after hydrolysis

The data regarding the obtained components and their concentrations in the solutions studied are presented in Table 2.
According to the data presented in Table 2 all the studied standard compounds were identified in the tested methanol extract $(7,8,13)$. The dominant components were apigenin-7-glucoside and chlorogenic acid with concentration of $0.75701 \%$ and $0.51378 \%$, respectively. Luteolin, caffeic acid, luteolin-7-glucoside and hyperoside were identified in lower concentration $-0.13217 \%, 0.05216 \%, 0.03117 \%$ and $0.00087 \%$, respectively. Rutin and rosmarinic acid were represented in the tested solution only in trace amounts.

According to the data represented in Table 2, only 4 compounds - apigenin-7-glucoside, luteolin, chlorogenic acid and luteolin-7-glucoside were identified in the extract after hydrolysis. The concentration of the compounds mentioned above was $0.16639 \%$, $0.02468 \%, 0.00563 \%$ and $0.00242 \%$, respectively.

\section{CONCLUSIONS}

New remedies and diet supplements are appearing on the pharmaceutical market in Ukraine and abroad. The conducted research enables further standardization of artichoke-containing drugs and products based on the data provided below.

1. The application of HPLC GC/MS method of analysis helped to work out a technique of detection of 8 biologically active compounds in dry artichoke flower heads extracts.

2. Methanol dry artichoke flower heads extract and methanol dry artichoke flower heads extract after hydrolysis were analyzed with the

Table 2. Results of a quantitative determination of the studied components in methanol and artichoke extracts after hydrolysis

\begin{tabular}{lcc} 
& Artichoke extract after hydrolysis & Methanol artichoke extract \\
Studied component & \multicolumn{1}{c}{ Content in \%, based on a dry substance } \\
Luteolin & 0.02468 & 0.13217 \\
Chlorogenic acid & 0.00563 & 0.51378 \\
Apigenin-7-glucoside & 0.16639 & 0.75701 \\
Luteolin-7-glucoside & 0.00242 & 0.03117 \\
Hyperoside & trace amount & 0.00087 \\
Rutin & trace amount & trace amount \\
Caffeic acid & trace amount & 0.05216 \\
Rosmarinic acid & trace amount & trace amount \\
\hline
\end{tabular}


Andrei Fedosov, Oleksandra Kyslychenko, Andrei Gudzenko et all.

help of the developed technique. As the result of the conducted research luteolin-7-glucoside, luteolin, apigenin-7-glucoside, hyperoside, rutin, caffeic acid, chlorogenic acid and rosmarinic acid were identified in the studied methanol extract. Wherein, apigenin-7-glucoside and chlorogenic acid were present at the highest amount- $0.75701 \%$ and $0.51378 \%$ based on a dry substance, respectively.

3. Only four compounds - apigenin-7-glucoside, luteolin, chlorogenic acid and luteolin-7-glucoside were identified in the studied extract after hydrolysis. The concentration of the compounds mentioned above was $0.16639 \%$, $0.02468 \%, 0.00563 \%$, and $0.00242 \%$ based on dry substance, respectively.

4. HPLC technique is the validated quality control technique of the obtained extract.

\section{REFERENCES}

1. Behara RY. Pharmacological studies on artichoke leaf extract - An edible herb of Mediterranean origin. JPBMS. 2011;11(11):1-5.

2. Chernova YeM, Baranskaya YeK, Lemeshko ZA, Mayevskaya MV, Ivashkin VT. Options of thistle leaves extract application at functional dyspepsia. Clinical perspectives of gastroenterology, hepatology. 2014;5:21-7 (in Russian).

3. Englisch W, Beckers C, Unkauf M, Ruepp M, Zinserling V. Efficacy of artichoke dry extract in patients with hyperlipoproteinemia. Arzneim-Forsch. 2000;50:260-5.

4. Fantini N, Colombo G, Giori A, Riva A, Morazzoni P, Bombardelli E, et al. Evidence of glycemialowering effect by a Cynara scolymus L. extract in normal and obese rats. Phytother Res. 2011;25(3):463-6.

5. Fintelmann V. Therapeutic profile and mechanism of action of artichoke leaf extract: hypolipemic, antioxidant, hepatoprotective and choleretic properties. Phytomed. 1996;Supplement 1:50.

6. Gebhardt R. Anticholestatic activity of flavonoids from artichoke (Cynara scolymus L.) and of their metabolites. Med Sci Monit. 2001;7 Suppl 1:316-20.

7. Gudzenko A. Development and validation of a RPHPLC method for the simultaneous determination of luteolin and apigenin in herb of Achillea millefolium L. The pharma innovation - journal. 2013;2(7): 7-14.

8. Häusler M, Ganzera M, Abel G, Popp M, Stuppner $H$. Determination of caffeoylquinic acids and flavonoids in Cynara scolymus L. by high perfomance liquid chromatography. Chromatographia. 2002; 56(7/8): 407-11.

9. Holtmann G, Adam B, Haag S, Collet W, Grünewald E, Windeck T. Efficacy of artichoke leaf extract in the treatment of patients with functional dyspepsia: a six-week placebo-controlled, double-blind, multicentre trial. Aliment Pharmacol Ther. 2003;18(11-12):1099-105.

10. Lim TK. Edible Medicinal And Non-Medicinal Plants: Volume 7, Flowers. Netherlands: Springer; 2014.

11. Llorach R, Espín JC, Tomás-Barberán FA, Ferreres F. Artichoke (Cynara scolymus L.) byproducts as a potential source of health-promoting antioxidant phenolics. J Agric Food Chem. 2002;50(12):3458-64.

12. Mocelin R, Marcon M, Santo GD, Zanatta La, Sachett A, Schönell AP, et al. Hypolipidemic and antiatherogenic effects of Cynara scolymus in cholesterol-fed rats. Revista Brasileira de Farmacognosia. 2016;26(2):233-9.

13. Sarawek S, Butterweck V, Feistel B, Pischel I. Flavonoids of Cynara scolymus possess potent xanthinoxidase inhibitory activity in vitro but are devoid of hypouricemic effects in rats after oral application. Planta Medica. 2008;74(3):221-7.

14. Wegener T, Fintelmann V. Pharmacological properties and therapeutic profile of artichoke (Cynara scolymus L.). Wien Med Wochenschr. 1999;149(810):241-7 (in German).

15. Ziai SA, Dastpak A, Poorhoseini L, Hemati AR, Naghdi Badi H, Gharavi Naene M. Review on Cynara scolymus L. Journal of Medicinal Plants. 2005;4(13):1-10. 